\title{
Effects of follicular phase exercise on luteinizing hormone pulse characteristics in sedentary eumenorrhoeic women
}

Nancy I. Williams, Janet W. McArthur, Barry A. Turnbull, Beverly A. Bullen, Gary S. Skrinar, Inese Z. Beltins, G. Michael Besser, Lesley H. Rees, Ian Gilbent, Derek Cramer, Lesile Perry and Dan S. Tunstall Pedoe Departments of Endocrinology, Chemical Endocrinology and Reproductive Physiology, and Cardiac Department of St. Bartholomew's Hospital, London; Pulmonary Function Laboratory, Royal Brompton Hospital, London; Department of Pediatrics, University of Michigan, Ann Arbor, MI; and the Department of Health Sciences, Sargent College, Boston University, Boston, Mass., USA

(Received 8 March 1994; returned for revision 25 April 1994; finally revised 26 May 1994; accepted 18 June 1994)

\section{Summary}

OBJECTIVE Current studies reveal Iltile regarding the Inception of exerclse-Induced LH changes during physlcal training. Thls study almed to assess the susceptiblilty of the hypothalamic-pitultary axis to the acute physical stress of exercise In untralned, physically Inactive women. The acute effects of submaximal endurance exercise upon the pulsatile LH secretion In the follicular phase were compared with those accompanying lelsurely strolling for a similar time period.

sUBJECTS All subjects were eumenorrhoelc, as determined by biphasic temperature patterns, detection of the urinary LH surge, and mid-luteal serum progesterone levels. Subjects were not physically active and had little history of strenuous exercise $\left(\mathrm{VO}_{2} \max =38.0 \pm 1.8\right)$ (mean \pm SEM) $\mathrm{ml} / \mathrm{kg} / \mathrm{min}$ ).

DESIGN All women completed a 13-5-hour pulsatility test which Included three consecutive 20 -minute runs on a treadmill at 50, 60 and $70 \%$ of the subjects' maximum oxygen uptake $(n=16)$. Six of these same subjects completed a separate test on another occasion In which one hour of leisurely strolling was substltuted for exercise. Blood was sampled every 10 minutes via an indwelling cannula for 4.5 hours before and 8 hours after one hour of exerclse and or strolling.

MEASUREMENTS A pulse algorithm (Pulsar) was used to quantity LH pulse characteristics.

Correspondence: Dr Nancy I. Williams, Primate Research Laboratory, University of Pittsburgh, 709 New Texas Road, Pittsburgh, PA 15239, USA.
RESULTS Exercise produced no significant effects upon LH pulse frequency or mean serum LH concentration. However, exerclse of moderate Intensity caused a signiflcant Increase in LH pulse amplitude $(P<0.05)$. Strolling produced no significant changes in LH secretion. CONCLUSION Acute exercise of moderate intensity in the follicular phase of untralned women is an Insufficlent stimulus to inhlbit the GnRH pulse generator in the postexercise period, yet may produce a slight stimulatory effect on the amount of LH released per pulse

While strenuous endurance training is associated with an increased prevalence of secondary amenorrhoea (Feicht et al., 1978; Sanborn et al., 1982), anovulation (Pirke et al., 1990), and luteal phase defects (Bullen et al., 1985; Beitins et al., 1991), the mechanisms involved are not fully understood. Presumably, reproductive hormonal disturbances involve a central mechanism whereby a single stress or many stressors associated with exercise training impinge(s) upon the functioning of the gonadotrophin-releasing hormone $(\mathrm{GnRH})$ pulse generator leading to an alteration in luteinizing hormone (LH) secretion, and ultimately to reduced gonadotrophic support to the ovary. Most (Baker 1981; Ronkainen, 1985), but not all (Loucks et al., 1989; Boyden et al., 1984) studies of females with exercise-induced amenorrhoea have found low levels of gonadotrophin secretion when compared to sedentary eumenorrhoeic women. Studies of basal LH pulse characteristics have shown a chronic suppression of LH pulse frequency in severely amenorrhoeic and oligomenorrhoeic runners (Veldhuis et al., 1985; Loucks, 1989) and in anovulatory athletes (Pirke et al., 1990). A slowed LH pulse frequency along with decreased (Cumming et al., 1985a) or increased (Loucks, 1989) pulse amplitude have been reported in eumenorrhoeic athletes, and eumenorrhoeic athletes with low luteal phase urinary pregnenadiol glucuronide concentrations, respectively. Regarding the acute effects of exercise, in trained eumenorrhoeic women who exercised in the mid to late follicular phase, an immediate, post-exercise reduction in LH pulse frequency (Cumming et al., 1985b) and in another instance, amplitude (Keizer et al., 1987) have been reported. Based on these data, it is conceivable that the acute effects of exercise on LH secretion gradually become chronic as training progressively increases. However, studies of basal or post-exercise LH secretion in already well trained 
Table 1 Characteristics of subjects in exercise and strolling studies $(n=16)$

\begin{tabular}{|c|c|c|c|c|c|c|c|c|}
\hline & \multirow{2}{*}{$\begin{array}{c}\text { Age } \\
\text { (years) }\end{array}$} & \multirow{2}{*}{$\begin{array}{l}\text { Height } \\
(\mathrm{cm})\end{array}$} & \multirow{2}{*}{$\begin{array}{l}\text { Weight } \\
(\mathrm{kg})\end{array}$} & \multirow[b]{2}{*}{ Percentage body fat } & \multicolumn{2}{|c|}{$\mathrm{VO}_{2} \max$} & \multirow{2}{*}{$\begin{array}{c}\text { Age of menarche } \\
\text { (years) }\end{array}$} & \multirow{2}{*}{$\begin{array}{c}\text { Time since } \\
\text { menarche } \\
\text { (years) }\end{array}$} \\
\hline & & & & & $(1 / \mathrm{min})$ & $\mathrm{ml} \mathrm{O}_{2} / \mathrm{kg} \mathrm{BW}$ & & \\
\hline $\begin{array}{l}\text { Mean } \\
\text { (SEM) } \\
\text { Range }\end{array}$ & $\begin{array}{c}27 \\
(1) \\
(19-35)\end{array}$ & $\begin{array}{c}161 \cdot 4 \\
(2 \cdot 7) \\
(153-173)\end{array}$ & $\begin{array}{c}54 \cdot 1 \\
(3 \cdot 7) \\
(44-67)\end{array}$ & $\begin{array}{c}26 \cdot 7 \\
(1 \cdot 0) \\
(21-32)\end{array}$ & $\begin{array}{c}2 \cdot 15 \\
(0.12) \\
(1 \cdot 22-2 \cdot 87)\end{array}$ & $\begin{array}{c}38 \cdot 0 \\
(1 \cdot 8) \\
(24 \cdot 2-47 \cdot 4)\end{array}$ & $\begin{array}{c}11 \cdot 3 \\
(1 \cdot 1) \\
(11-17)\end{array}$ & $\begin{array}{c}14 \cdot 1 \\
(1 \cdot 5) \\
(7-24)\end{array}$ \\
\hline
\end{tabular}

athletes do not clarify the role of exercise stress per se, and reveal little regarding the inception of exercise induced changes in LH secretion, that is, whether changes in $\mathbf{L H}$ secretion might occur at the very onset of training, or if other metabolic/neuroendocrine adaptations associated with later stages of training play a role.

The aim of this study was to address the susceptibility of the hypothalamic-pituitary axis to the acute physical stress of exercise in untrained, physically inactive women. Only one study to date has examined the effects of submaximal exercise on $\mathrm{LH}$ pulse parameters in untrained women (McArthur et al., 1990). This study, conducted in the midluteal phase, disclosed no changes in LH pulse characteristics after one hour of moderately fast treadmill running by normally sedentary, eumenorrhoeic women. The present study, conducted in the mid-follicular phase, was designed to complement the previous investigation and employed essentially the same format. It was performed as a joint investigation in the Department of Endocrinology, St Bartholomew's Hospital, London, and the Department of Health Sciences, Sargent College of Allied Health Professions, Boston University, Boston, Massachusetts, 11 subjects being studied in London and five in Boston.

\section{Methods and materials}

\section{Subjects}

Sixteen healthy, normally menstruating women between the ages of 19 and $35(27 \pm 1$ years) (mean \pm SEM) at least 7 years since menarche $(14 \cdot 1 \pm 1 \cdot 5$, mean \pm SEM), who did not engage in regular physical activity, were recruited (Table 1). The investigation was approved by the ethics committees of the two institutions, and all subjects gave written informed consent.

Screening included a detailed history and physical examination, pelvic examination, routine blood indices and endocrine screening that included determinations of serum luteinizing hormone (LH), follicle stimulating hormone, prolactin, thyroxine (T4), free T4 index and sex hormone binding globulin. All subjects exhibited a midcycle $\mathrm{LH}$ peak as confirmed with a urinary $\mathrm{LH}$ detection kit (First Response, Tambrands, Inc.) and a biphasic body temperature pattern throughout the study. All women in the study had a luteal phase length of at least 9 days as measured from the $\mathrm{LH}$ peak and three mid-iuteal serum progesterone levels of at least $17 \mathrm{nmol} / \mathrm{l}$. Prior use of oral contraceptives within the last 6 months, narcotics and sedatives were criteria for exclusion. Means for height, weight, percentage body fat as determined by skin-fold measurements (Sloan et al., 1962) and maximal aerobic capacity ( $\mathrm{VO}_{2}$ max) were typical of sedentary women in their age range. Completion of physical activity questionnaires revealed that subjects were not currently training and that most had little history of regular physical activity.

Maximal aerobic capacity $\left(\mathrm{VO}_{2} \max (\mathrm{ml} / \mathrm{kg} / \mathrm{min})\right)$ was determined with a graded treadmill test to exhaustion, using the measurement of metabolic gas exchange and minute volume by mass spectrometry alone (Davies \& Denison, 1979). The initial treadmill speed was $3 \mathrm{~km} / \mathrm{h}$ and increased $1 \mathrm{~km} / \mathrm{h}$ every 3 minutes. The treadmill remained level throughout. Criteria for the attainment of $\mathrm{VO}_{2}$ max included a plateau in oxygen uptake and in heart rate despite an increase in exercise intensity, along with a final respiratory quotient in excess of 1 .

\section{Study design}

All subjects completed a 13.5-hour pulsatility test in the mid-follicular phase on days $4-9$ of the cycle $(7 \pm 0.4$ (mean \pm SEM)) which included one hour of progressive exercise at approximately $50 \%(20 \mathrm{~min}), 60 \%(20 \mathrm{~min})$ and $70 \%(20 \mathrm{~min})$ of their predetermined $\mathrm{VO}_{2} \max$. To serve as a control for effects of changes in posture and cannulation, six of these same individuals completed an additional 13.5-hour test during the mid-follicular phase (days $4-8 ; 6.7 \pm 0.5$ (mean \pm SEM)) of another menstrual cycle, with leisurely strolling substituted for exercise. For these subjects, the order of trials was randomized. Each subject was familiarized with the testing protocol before undertaking a treadmill 
run. Appropriate treadmill speeds representing 50,60 and $70 \%$ of each subject's maximal oxygen uptake were determined from their initial $\mathrm{Vo}_{2} \max$ test. Heart rates were determined each minute during exercise with the use of standard electrocardiographic techniques. Ratings of general perceived exertion (RPE) using the Borg scale (Borg, 1970) were obtained at the end of each successive 20-minute period. Subjects were permitted to drink water and rest briefly after each bout of exercise while the blood sample was being taken. Lactate, haematocrit and haemoglobin levels were determined before and immediately after exercise, and before and after strolling in the control trial. Plasma lactate was analysed using a YSL 23 Lactate Analyzer (Leavy et al., 1985).

\section{Blood sampling}

The subjects reported to the metabolic ward of St Bartholomew's Hospital, London or to the Thorndike Clinical Research Center in the Boston City Hospital at approximately $0800 \mathrm{~h}$ for antecubital venous cannulation. Sampling $(1.5 \mathrm{ml})$ for $\mathrm{LH}$ commenced at 10 -minute intervals at least one hour later and continued until exercise or strolling began between 1330 and $1430 \mathrm{~h}$. During exercise or strolling, one sample was obtained after each of three 20 minute periods. After exercise or strolling, sampling was resumed at 10-minute intervals until approximately $2230 \mathrm{~h}$. Meals were provided according to the routine hospital schedule. Sleep was prevented.

\section{Hormone assays}

Blood samples were allowed to clot at room temperature and the serum stored at $-20^{\circ} \mathrm{C}$. In the subjects tested in London ( $n=11$ ), the method of Grossman et al. (1981) was employed for the radioimmunoassay of LH. The antibody (F 87/2) (Lynch \& Shirley, 1975) was kindly provided by Professor Wilfred Butt, and the separation was facilitated by polyethylene glycol. The serum LH values are expressed as IU/1, using the WHO International Pituitary LH Standard $(68 / 40)$ as the reference preparation. The intra and interassay coefficients of variation were 3.7 and $4.9 \%$, respectively. The five subjects tested in Boston (all in the exercise group), had LH measured as described by Midgley $e t$ al. (1964), with intra and inter-assay coefficients of variation of 9.0 and $17.0 \%$, respectively. The antiserum 391 supplied by the Standard and Reagents Core, Reproductive Sciences Program, University of Michigan, was anti-hCG raised in rabbit and diluted 1:80,000 in PBS. Values for these subjects are expressed as $\mathrm{IU} / 1$ according to the WHO 2nd International Reference Preparation of pituitary LH
(78/549). All samples from a given subject were analysed in the same assay. The two assay standards used in the radioimmunoassays were compared to establish relative potency. A five-point linear regression analysis was performed and both standard curves exhibited linearity $(P<0.0001)$ within the normal range of $\mathrm{LH}$ values. When slopes $(78 / 549:-19.8 \pm 2.9 ; 68 / 40:-19.1 \pm 0.4$ (mean $\pm \mathrm{SD}$ )) of regression lines were compared, a test of non-parallelism was not significant $(P=0 \cdot 800)$. Data were normalized from the 78/549 standard (Boston) to the $68 / 40$ standard (London) by multiplication by 1.19 (ratio of the intercepts). The 78/549 standard (Boston) exhibits parallelism when compared to the standard used in a modification of the in-vitro bioassay method of Dufau et al. (1976). The relative potency (ratio of $\mathrm{LH}$ bioactivity to $\mathrm{LH}$ immunoactivity) is approximately $2 \cdot 2-2.8$ when samples from the early to mid-follicular phase of sedentary women are assessed. No data are available to establish the relative biopotency of the London radioimmunoassay standard. An analysis of variance (ANOVA) revealed no significant differences in LH pulse parameters attributable to the assay method. It should be emphasized that possible differences in results due to assay method are minimal because the statistical comparisons performed on $\mathrm{LH}$ data describe intra-subject changes, i.e., pre to post-exercise. Values for LH obtained during exercise were corrected for changes in plasma volume, using the method of Dill and Costill (1974).

\section{Pulse analysis and statistics}

The Pulsar program was used to identify LH pulses and to quantify their characteristics. This program was substituted for that of Henery et al. (1989), which was employed for the analysis of our previous study (McArthur et al., 1990) and which was suited to the shape of luteal phase pulses, but not to those occurring during the follicular phase. The Pulsar $G$ values empirically derived from the four original $\mathrm{LH}$ calibration sets were used: $G(1)=3.80, G(2)=2.60$, $G(3)=1.90, G(4)=1.50$ and $G(5)=1 \cdot 20$. These settings were associated with a $5 \cdot 1 \%$ false-positive detection and a $5.9 \%$ false-negative detection rate when LH data sets in the original reference were analysed with Pulsar and compared to peaks chosen visually (Merriam \& Wachter, 1982). In a review by Urban et al. (1988), Pulsar showed a false-positive rate of less than $0.1 \%$ when run on a synthetic data set of signal-free noise designed to simulate the distribution of a range of assay standard deviations. When early and late follicular phase LH pulse patterns were also analysed by Pulsar (using the above-stated $G$-values) and six other pulse detection algorithms, the number of pulses and pulse 


\begin{tabular}{|c|c|c|c|c|c|c|}
\hline Stage & $\% V_{O_{2}} \max$ & $\begin{array}{c}V \mathrm{O}_{2} \\
\left(\mathrm{ml} / \mathrm{O}_{2} / \mathrm{kg} \mathrm{BW}\right)\end{array}$ & $\begin{array}{l}\text { Speed } \\
(\mathrm{km} / \mathrm{h})\end{array}$ & $\begin{array}{l}\text { Heart rate } \\
\text { (bpm) }\end{array}$ & $\mathrm{RPE}^{*}$ & $\begin{array}{r}\text { Lactate } \\
(\mathrm{mmol} / \mathrm{l})\end{array}$ \\
\hline I & 50 & $\begin{array}{l}18.9 \\
(0.9)\end{array}$ & $\begin{array}{c}6.0 \\
(0.2)\end{array}$ & $\begin{array}{l}127 \\
(8)\end{array}$ & $\begin{array}{c}9.3 \\
(0.4)\end{array}$ & - \\
\hline II & 60 & $\begin{array}{l}22 \cdot 7 \\
(1 \cdot 0)\end{array}$ & $\begin{array}{c}7 \cdot 1 \\
(0 \cdot 2)\end{array}$ & $\begin{array}{l}156 \\
(4)\end{array}$ & $\begin{array}{l}13 \cdot 2 \\
(0 \cdot 6)\end{array}$ & - \\
\hline III & 70 & $\begin{array}{l}26 \cdot 4 \\
(1-2)\end{array}$ & $\begin{array}{c}8 \cdot 2 \\
(0 \cdot 2)\end{array}$ & $\begin{array}{l}176 \\
(4)\end{array}$ & $\begin{array}{l}16 \cdot 0 \\
(0.6)\end{array}$ & $\begin{array}{l}3.70 \dagger \\
(0.5)\end{array}$ \\
\hline
\end{tabular}

Table 2 Exercise data

Values are mean (SEM).

*RPE, rating of perceived exertion.

$\dagger P<0.05$ us pre-exercise levels; paired $t$-test; $n=11$.

amplitudes detected were statistically indistinguishable between programs (Evans et al., 1992).

Pulse variables analysed include pulse frequency (pulses/h), maximal peak amplitude (IU/1), incremental peak amplitude (IU/I) and peak area (IU/1/peak). For a given peak, maximal peak amplitude (IU/1) represents the highest absolute value within the peak. Incremental peak amplitude (IU/I) represents the highest point in a peak relative to a calculated baseline, i.e. maximal peak amplitude - baseline. Area for a given peak was determined by calculating the average rise above baseline and multiplying by the number of minutes over which the peak extended.

To examine the acute effects of exercise on LH secretion, an average of each pulse parameter was computed for each subject, during the pre-exercise (or pre-strolling) time period and during the post-exercise (or post-strolling) time period.

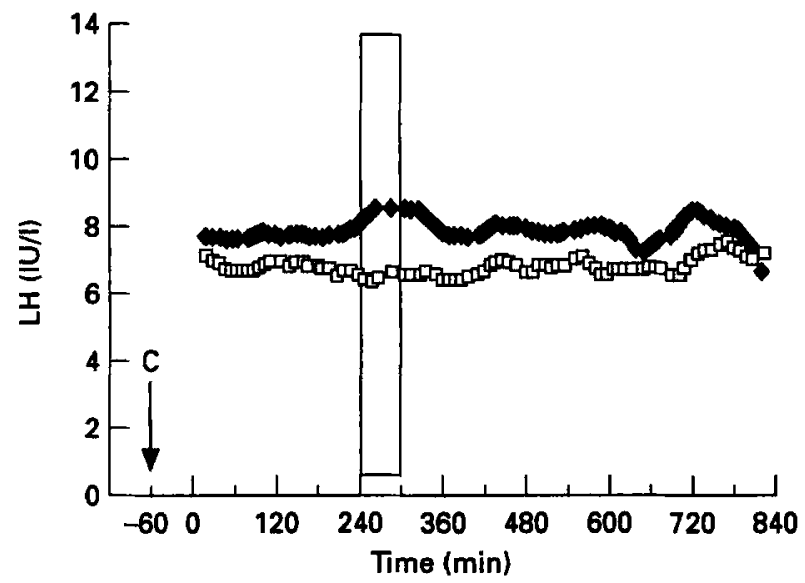

Fig. 1 Composite smoothed mean LH concentrations for $\square$, the exercise $(n=16)$ and $\square$, non-exercise $(n=6)$ studies. Cannula insertion is indicated by an arrow, with blood sampling commencing $1 \mathrm{~h}$ later at time 0 . The bar shows the period of exercise.
Group means were then compared using Student's paired $t$-tests. Pulse frequency and amplitude of pulses that occurred during exercise were not included in the analysis because the short duration of exercise precluded the certain capture of a pulse or pulses within that time period. Mean serum LH was analysed before, during and after exercise or strolling using a one-way ANOVA with repeated measures. Significance was defined as $P<0.05$.

To address whether the stress of cannulation and or the anticipation of exercise (or strolling) produced changes in LH pulse characteristics, data were also quantified during the 2 hours after cannulation and the 2 hours immediately prior to exercise.

\section{Results}

\section{Exercise data}

The estimated levels of oxygen uptake, corresponding treadmill speeds and actual physiologic data representing each stage of exercise are shown in Table 2. Heart rates were averaged over the last 5 minutes of each stage. Ratings of perceived exertion were obtained at the end of each stage. Scores of 9, 13, and 16 correspond to very light, somewhat hard, and between hard and very hard levels of exertion, respectively. Lactate values rose from a mean resting level of 1.20 to $3.70 \mathrm{mmol} / 1$ at the conclusion of exercise.

\section{LH secretion}

Figure 1 is a composite graph of mean $\mathbf{L H}$ (smoothed as a moving average over seven points) before, during and after exercise and strolling. The two curves exhibit no striking differences apart from a slight rise in LH during exercise in the exercise group. The mean $\pm S E M$ values for the exercise and strolling studies for each $\mathrm{LH}$ parameter as determined using Pulsar are depicted in Table 3. No significant changes 
Table 3 LH pulse parameters

\begin{tabular}{|c|c|c|c|c|c|c|c|c|c|c|c|}
\hline & \multicolumn{2}{|c|}{$\begin{array}{l}\text { Frequency } \\
\text { (pulses/h) }\end{array}$} & \multicolumn{2}{|c|}{$\begin{array}{c}\text { Maximal } \\
\text { peak amplitude } \\
\text { (IU/l) }\end{array}$} & \multicolumn{2}{|c|}{$\begin{array}{c}\text { Incremental } \\
\text { peak amplitude } \\
\text { (IU/l) }\end{array}$} & \multicolumn{3}{|c|}{$\begin{array}{c}\text { Mean LH } \\
(\mathrm{IU} / \mathrm{l})\end{array}$} & \multicolumn{2}{|c|}{$\begin{array}{l}\text { Peak area } \\
\text { (IU/peak) }\end{array}$} \\
\hline & Pre & Post & Pre & Post & Pre & Post & Pre & During & Post & Pre & Post \\
\hline $\begin{array}{l}\text { Exercise } \\
(n=16)\end{array}$ & $\begin{array}{c}0.98 \\
(0.08)\end{array}$ & $\begin{array}{c}0.95 \\
(0.07)\end{array}$ & $\begin{array}{c}8 \cdot 81 \\
(0 \cdot 66)\end{array}$ & $\begin{array}{c}9.45^{*} \\
(0.67)\end{array}$ & $\begin{array}{c}2.66 \\
(0.23)\end{array}$ & $\begin{array}{c}3.09 " \\
(0.33)\end{array}$ & $\begin{array}{c}7 \cdot 28 \\
(0.59)\end{array}$ & $\begin{array}{c}7.85 \\
(0.72)\end{array}$ & $\begin{array}{c}7.65 \\
(0.57)\end{array}$ & $\begin{array}{l}76 \cdot 4 \\
(8 \cdot 3)\end{array}$ & $\begin{array}{l}88 \cdot 2 \\
(9 \cdot 6)\end{array}$ \\
\hline $\begin{array}{l}\text { Strolling } \\
(n=6)\end{array}$ & $\begin{array}{c}0.82 \\
(0.10)\end{array}$ & $\begin{array}{c}0.84 \\
(0.08)\end{array}$ & $\begin{array}{c}7.83 \\
(0.63)\end{array}$ & $\begin{array}{c}7.53 \\
(0.57)\end{array}$ & $\begin{array}{c}2.47 \\
(0.46)\end{array}$ & $\begin{array}{c}2.25 \\
(0.21)\end{array}$ & $\begin{array}{c}6.44 \\
(0.62)\end{array}$ & $\begin{array}{c}6.62 \\
(0.56)\end{array}$ & $\begin{array}{c}6.45 \\
(0.71)\end{array}$ & $\begin{array}{c}84 \cdot 4 \\
(18 \cdot 6)\end{array}$ & $\begin{array}{c}76 \cdot 1 \\
(11.4)\end{array}$ \\
\hline
\end{tabular}

Values are mean (SEM).

$* P<0.05$ vs pre-exercise levels; paired $t$-test.

in LH pulse characteristics occurred due to strolling. One hour of moderate intensity exercise did not affect $\mathrm{LH}$ pulse frequency $(0.98 \pm 0.08$ to $0.95 \pm 0.07$ (mean \pm SEM); pre vs post exercise, respectively). Thirteen out of 16 subjects exhibited a pulse during the hour of exercise, and in the three subjects who did not pulse during their run, a secretory episode was present immediately before or just after exercise. However, exercise did produce small but significant increases in maximal peak amplitude $(8.81 \pm 0.66$ to $9.45 \pm 0.67 \mathrm{IU} / 1$ (mean $\pm \mathrm{SEM}$ ); $P<0.05$ ) and in incremental peak amplitude $(2.66 \pm 0.23$ to $3.09 \pm 0.33 \mathrm{IU} / 1$ $(P<0.05))$. Data from a representative subject are depicted in Fig. 2. In this subject, maximal peak amplitude increased from $9 \cdot 86$ to $10 \cdot 60 \mathrm{IU} / 1$ and incremental peak amplitude

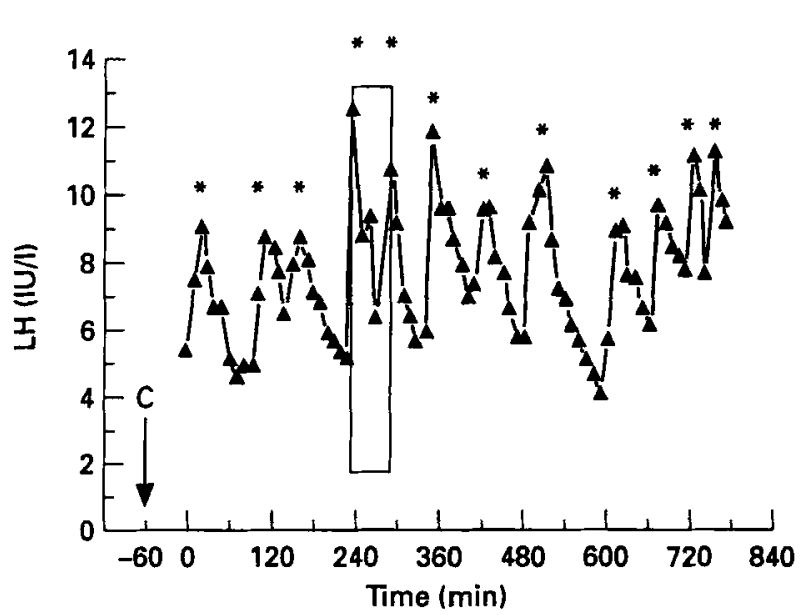

Flg. 2 Representative data from a subject depicts an exercise induced rise in LH pulse amplitude. The bar shows the period of exercise; pulses confirmed by Pulsar are noted by asterisks. increased from 4.35 to $4.61 \mathrm{IU} / \mathrm{l}$, while pulse frequency was 0.93 peaks $/ \mathrm{h}$ before exercise and 0.84 peaks $/ \mathrm{h}$ after exercise. In the exercise group, peak area was $76.4 \pm 8.3 \mathrm{IU} /$ peak before exercise, and $88.2 \pm 9 \cdot 6 \mathrm{IU} /$ peak after exercise. Mean serum LH levels did not change significantly with exercise. A further analysis was performed in view of our previous finding of a possible post-cannulation suppression of $\mathrm{LH}$ secretion in both groups (strolling and exercise) during the luteal study. No significant differences existed in pulse parameters during the 2 hours after cannulation compared to the 2 hours before exercise or strolling. In addition, a pulsatile episode occurred within 90 minutes of cannulation in all but one subject during one occasion.

\section{Dlecussion}

Strenuous exercise training that is begun abruptly has been shown to induce luteal phase insufficiency, luteal shortening and anovulation (Bullen et al., 1985; Beitins et al., 1991). Even low intensity recreational running that does not disturb luteal phase length initiates luteal inadequacy (Ellison \& Lager, 1986). Little is known regarding the time course of the associated hormonal changes. Previous studies suggest that oligomenorrhoea (Veldhuis \& Johnson, 1985) and amenorrhoea (Loucks et al., 1989) are accompanied by an inhibition of the GnRH pulse generator, manifested by a reduction in LH pulse frequency. Few prospective studies attempting to document the evolution of exercise-induced menstrual disturbances (Bullen et al., 1985; Boyden et al., 1984; Keizer et al., 1987) have been performed, and only one (Rogol et al., 1992), has measured LH pulsatile parameters successively with training. In the latter study, women gradually increased their training over a year, and exhibited only a slight decrease in luteal phase length ( $<2$ days) with no concomitant changes in basal LH pulse parameters, 
suggesting that substantial changes in reproductive function and associated changes in LH secretion may require a more severe exercise regimen. If acute exercise early in training proves to have little effect on LH secretion, it is likely that other factors associated with training adaptations rather than the immediate effects of exercise itself are responsible for the chronic suppression of LH secretion associated with menstrual disturbances. Alternatively, if isolated bouts of exercise do affect LH secretion patterns, these effects may become chronic with the repetition that occurs with daily training. They might then initiate the evolution of abnormal follicular maturation and ultimately progress to amenorrhoea.

The purpose of this study was to determine whether follicular LH secretion is altered upon pre-training exposure to the stress of a single bout of exercise. Our results agree with those of the complementary study performed during the luteal phase (McArthur et al., 1990) in that no acute exercise-induced suppression of $\mathrm{LH}$ frequency was identified when subjects exercised for one hour at a moderate intensity. Suppression of pulse frequency may require more intensive exercise of longer duration, or may not occur until influenced by chronic metabolic and/or neuroendocrine changes resulting from repetitive training. Unlike luteal phase exercise, follicular phase exercise of moderate intensity was found to exert a slight stimulatory effect upon LH secretion in our untrained women. While the rate of LH pulsations was unaffected, the amplitude of the LH peaks was significantly increased after exercise. The physiological significance of a change of the magnitude observed in this study is unknown. Differential effects of GnRH pulse frequency and amplitude have been shown regarding gonadotrophin subunit mRNA concentrations in castrate, testosterone-replaced rats (Marshall et al., 1991). It is difficuit to explain with certainty why LH responses to acute exercise would differ with menstrual cycle phase. Variations in circulating steroid levels may have differential effects on the sensitivity of the GnRH pulse generator to excitatory stimuli evoked by exercise, or perhaps play a role at the level of the pituitary by modifying its responsiveness to GnRH. Cyclic changes in other neuromodulatory systems, e.g. opioids, may conceivably cause alterations in GnRH secretion with exercise. Additionally, slight stimulatory effects of exercise may be more difficult to detect in the luteal phase, when the basal frequency of LH pulsations is less and the amplitude of pulses is greater and more variable than in the follicular phase.

The present finding of a slight exercise-induced stimulation of LH agrees with others who have reported an increase in follicular phase LH after exercise (Kuoppasalmi et al., 1980; Schmid et al., 1982; Baker, 1982). However, many of these studies did not examine pulse characteristics and were performed on trained individuals. Few studies have carefully examined the effect of acute exercise on pulsatile LH secretion. Keizer (1983) found an increase in early follicular pulse amplitude and pulse increment (relative difference between pulse peak and nadir) in four untrained but physically active women after four consecutive 15-minute bouts of stationary cycling at $60,70,80$ and $90 \%$ of $\mathrm{VO}_{2} \max$. However, a later report by Keizer and others (Keizer et al., 1987) documents a post-exercise reduction in follicular LH amplitude when exercise is preceded by several days of heavy training. Cumming et al. (1985b) observed a decrease in LH pulse frequency in the early follicular phase but no effect of 60 minutes of moderate intensity exercise on pulse amplitude in moderately trained women. In light of these conflicting results, it appears that the effects of acute exercise upon follicular LH pulsatility may be dependent on the training status of the subjects and possibly on the previous days' training regimen.

Studies examining the effects of chronic exercise on the responsiveness of the pituitary to exogenously administered GnRH also show conflicting results. Reduced responsiveness has been noted in male marathon runners (MacConnie et al., 1986), in female runners after weekly mileage had reached 50 miles/week (Boyden et al., 1984), and in the luteal phase of runners averaging 30 miles/week (Ronkainen, 1985). However, the cycling athletes studied by Loucks et al. (1989) had greater pulse amplitudes and a greater responsiveness to GnRH than their sedentary counterparts.

Inconsistencies in the reported literature may reflect a continuum of training induced changes in pulse amplitude and/or underscore the complexity of the control of $\mathrm{LH}$ secretion. Amplitude modulation can be achieved in several ways; (1) via the level of neuronal activity that influences the firing of the GnRH pulse generator, (2) by modulation of the stimulus-secretion coupling at the neurosecretory terminals (Lincoln et al., 1985) and (3) the responsiveness of the pituitary. As pointed out by Vermeulen and Kaufman (1992), gonadotroph responsiveness is influenced by a variety of factors, that is, the frequency of the GnRH pulses, their duration, the time elapsed since the last pulse, the hormonal environment and intrinsic gonadotroph sensitivity. The LH secretory rate and the distribution and elimination processes, with variable $\mathrm{LH}$ half-lives in different subjects, likewise affect the amplitude of the resulting LH pulse. A further complication is introduced by the polymorphism of circulating $\mathrm{LH}$, which results from the secretion of one or more endogenous isoforms with different bioactivity in individual subjects, the LH potency estimates of these isoforms being dependent upon antibody specifications of particular antisera. 
Significant variations occur in the steroid environment and in GnRH responsiveness according to the phase of the menstrual cycle as ovarian follicles wax and wane (Yen et al., 1972). Although we did not measure circulating oestrogen levels, follicular phase exercise of an intensity similar to that which we employed is known to be associated with a rise in serum oestrogen levels (Bonen et al., 1979; Jurkowski et al,, 1978), presumably due to diminished hepatic clearance. Whether an exercise-induced rise in oestradiol levels might increase the responsiveness of the pituitary to GnRH is doubtful considering the relatively short time of post-exercise exposure to increased levels and the fact that much higher levels of oestradiol are required to elicit a positive feedback response such as that occurring during the LH surge (Karsch et al., 1973).

Another potential factor, more likely but also more difficult to document in humans, is the effect of exercise on the release of central excitatory or inhibitory transmitters which influence the amount of GnRH released from the hypothalamus. This area of future study requires meticulous pharmacological studies in humans and the successful use of an animal model in which exercise is undertaken voluntarily that is, without undue exogenously applied stress (such as foot shock) in order to provide information regarding the effects of the physical stress of exercise alone. Future studies employing such an animal model, combined with advanced methodological techniques for in-vivo and in-vitro assessment, will no doubt reveal much about central mechanisms whereby acute and chronic exercise influence hypothalamic and pituitary function.

\section{Acknowledgements}

This study was supported, in part, by USPHS grants HD18999, MO-1 RR00503, the Sprague Fund and Tambrands, Inc. Dr J.W. McArthur was the recipient of a Fogarty International Fellowship in Endocrinology, a Medical Research Council Fellowship, and a fellowship from the London Sports Medicine Institute.

The authors are indebted to Drs Archie Young and P.J.A. Moult and Mr Robert Howell for advice concerning the design of the study, to Professor D.M. Denison for permission to use the facilities of the Pulmonary Function Laboratory at the Brompton Hospital, to Drs Nadia Debbas and Ray Carson for preliminary assessments of oxygen uptake, and to Mrs Pamela Richings and Mrs Eileen Collins for coordinating the phlebotomy teams at St Bartholomew's Hospital.

Serum LH levels for the Boston subjects were measured in Dr Inese Beitins' laboratory, with reagents supplied by the Standard and Reagents Core, Reproductive Sciences
Program, University of Michigan. Thanks are also due to the nursing staff of the General Clinical Research Center for obtaining the blood samples at the Boston City Hospital.

\section{References}

Baker, E.R. (1981) Menstrual dysfunction and hormonal status in athletic women: A review. Fertility and Sterility, 36, 691-696.

Baker, E.R. (1982) Plasma gonadotrophins, prolactin, and steroid hormone concentrations in female runners after a long-distance run. Fertility and Sterility, 38, 38-41.

Beitins, I.Z., McArthur, J.W., Turnbull, B.A., Skrinar, G.S. \& Bullen, B.A. (1991) Exercise induces two types of human luteal dysfunction: confirmation by urinary free progesterone. Journal of Clinical Endocrinology and Metabolism, 72, 1350-1358.

Bonen, A., Ling, W.Y., MacIntyre, K.P., Neil, R., McGrath, J.C. \& Belcastro, A.N. (1979) Effects of exercise on the serum concentrations of FSH, LH, progesterone and oestradiol. European Journal of Applied Physiology, 42, 15-23.

Borg, G.A., (1970) Perceived exertion as an indicator of somatic stress. Scandinavian Journal of Rehabilitation Medicine, 2, 92-98.

Boyden, T.W., Pamenter, R.W., Rotkis, T.C., Stanforth, P. \& Wilmore, J.H. (1984) Impaired gonadotropin responses to gonadotropin-releasing hormone in endurance-trained women. Fertility and Sterility, 41, 359-363.

Bullen, B.A., Skrinar, G.S., Beitins, I.Z., Mering, G., Turnbull, B.A. \& McArthur, J.W. (1985) Induction of menstrual disorders by strenuous exercise in untrained women. New England Journal of Medicine, 312, 1349-1353.

Cumming, D.C., Vickovic, M.M., Wall, S.R. \& Fluker, M.R. (1985a) Defects in LH release in normally menstruating runners. Journal Clinical Endocrinology and Metabolism, 60, 810-812.

Cumming, D.C., Vickovic, M.M., Wall, S.R., Fluker, M.R. \& Belcastro, A.N. (1985b) The effect of acute exercise on pulsatile release of luteinizing hormone in women runners. American Journal of Obstetrics and Gynecology, 152, 482-485.

Davies, N.J.H. \& Denison, D.M. (1979) The measurement of metabolic gas exchange and minute volume by mass spectrometry alone. Respiration Physiology, 36, 261-267.

Dill, D.B. \& Costill, D.L. (1974) Calculation of percentage changes in volumes of blood, plasma, and red cells in dehydration. Journal of Applied Physiology, 37, 247-248.

Dufau, M.L., Pock, R., Neubauer, A. \& Catt, K.J. (1976) In vitro bioassay of LH in human serum: the rat interstitial cell testosterone (RICT) assay. Journal of Clinical Endocrinology and Metabolism, 42, 958-969.

Ellison, P.T. \& Lager, C. (1986) Moderate recreational running is associated with lowered salivary progesterone profiles in women. American Journal of Obstetrics and Gynecology, 154, 1000-1003.

Evans, W.S., Sollenberger, M.J., Booth, R.A., Rogol, A.D., Urban, R.L., Carlsen, E.C., Johnson, M.L. \& Veldhuis, J.D. (1992) Contemporary aspects of discrete peak-detection algorithms. II. The paradigm of the luteinizing hormone pulse signal in women. Endocrine Reviews, 13, 81-104.

Feicht, C.B., Johnson, T.S., Martin, B.J., Sparkes, K.E. \& Wagner Jr, W.W. (1978) Secondary amenorrhea in athletes. Lancet, ii, $1145-1146$

Grossman, A., Moult, P.J.A., Gaillard, R.C., Delitala, G., Toff, W.D., Rees, L.H. \& Besser, G.M. (1981) The opioid control of 
LH and FSH release: effects of a met-enkephalin analogue and naloxone. Clinical Endocrinology, 14, 41-47.

Henerey, R.J., Turnbull, B.A., Kirkland, M., McArthur, J.W., Gilbert, I., Besser, G.M., Rees, L.H. \& Tunstall Pedoe, D.S. (1989) The detection of peaks in luteinizing hormone secretion. Chronobiology International, 6, 259-265.

Jurkowski, J.E., Jones, N.L., Walker, W.C., Younglai, E.V. \& Sutton, J.R. (1978) Ovarian hormonal responses to exercise. Journal of Applied Physiology: Respiration Environment Exercise Physiology, 44, 109-114.

Karsch, F., Weick, R.F., Butler, W.R., Dierschke, D.J., Krey, L.E., Wiess, G., Hotchkiss, J., Yamaji, T., \& Knobil, E. (1973) Induced LH surges in the Rhesus monkey: Strength-duration characteristics of the estrogen stimulus. Endocrinology, 92, 1740-1747.

Keizer, H.A. (1983) Doctoral Thesis: Hormonal responses in women as a function of physical exercise and training, University of Limburg, Maastricht, The Netherlands.

Keizer, H.A., \& Bonen, A. (1984) Exercise-induced changes in gonadotropin secretion patterns. International Journal of Sports Medicine, 5, 206-208.

Keizer, H.A., Menheere, P., Kuipers, H. \& Janssen, E. (1987) Changes in pulsatile LH secretion after exhaustive exercise and training. Medicine, Science, Sports and Exercise, 19, S55.

Kuoppasalmi, K., Naveri, H., Harkonen, M. \& Adlercreutz, H. (1980) Plasma cortisol, androsteniodene, testosterone and luteinizing hormone in running exercise of different intensities. Scandinavian Journal of Clinical Laboratory Investigation, 40, 403-409.

Leavy, J.A., Weil, M.H., Michacls, W.S., Astiz, M.E. \& Rackow, E.C. (1985) A technique for automated measurement of blood lactate at the bedside. Critical Care Medicine, 13, 323.

Lincoln, D.W., Fraser, H.M., Lincoln, G.A., Martin, G.B. \& McNeilly, A.S. (1985) Hypothalamic pulse generators. Recent Progress in Hormone Research, 41, 369-419.

Loucks, A.B., Mortola, J.F., Girton, L. \& Yen, S.S.C. (1989) Alterations in the hypothalamic-pituitary-ovarian and the hypothalamic-pituitary-adrenal axes in athletic women. Journal of Clinical Endocrinology and Metabolism, 68, 402-411.

Lynch, S.S. \& Shirley, A. (1975) Production of specific antisera to follicle-stimulating hormone and other hormones. Journal of Endocrinology, 65, 127-132.

MacConnie, S.M., Barkan, A., Lampman, R.M., Schork, M.A. \& Beitins, I.Z. (1986) Decreased hypothalamic gonadotropinreleasing hormone secretion in male marathon runners. New England Journal Medicine, 315, 411-417.

Marshall, J.C., Dalkin, A.C., Haisenleder, D.J., Paul, S.J., Ortolano, G.A. \& Kelch, R.P. (1991) Gonadotropin-releasing hormone pulses: Regulators of gonadotropin synthesis and ovulatory cycles. Recent Progress in Hormone Research, 47, 155-189.

McArthur, J.W., Gilbert, I., Henery, R.J., Quinn, J., Perry, L., Cramer, D., Kirkland, M., Tunstall Pedoe, D.S., Rees, L.H.,
Besser, G.M. \& Turnbull, B.A. (1990) The effects of submaximal endurance exercise upon LH pulsatility. Clinical Endocrinology, 32, 115-126.

Merriam, G.R. \& Wachter, K.W. (1982) Algorithm for the study of episodic hormone secretion. American Journal of Physiology, 243, E310-E318.

Midgley, Jr, A.R. (1964) Immunoassay of human gonadotropins: current status. Clinical Obstetrics and Gynecology, 10, 119-131, 1964.

Pirke, K.M., Schweiger, U., Broocks, A., Tuschl, R.J. \& Laessle, R.G. (1990) Luteinizing hormone and follicle stimulating hormone secretion patterns in female athletes with and without menstrual disturbances. Clinical Endocrinology, 33, 345-353.

Rogol, A.D., Weltman, A., Weltman, J.Y., Seip, R.L., Snead, D.B., Levine, S., Haskvitz, E.M., Thompson, D.L., Schurrer, Dowling, E., Walberg-Rankin, J., Evans, W.S. \& Veldhuis, J.D. (1992) Durability of the reproductive axis in eumenorrheic women during 1 yr of endurance training. Journal of Applied Physiology, 72, 1571-1580.

Ronkainen, H. (1985) Depressed follicle-stimulating hormone, leuteinizing hormone, and prolactin responses to the luteinizing hormone-releasing hormone, thyrotropin-releasing hormone, and metoclopramide test in endurance runners in the hardtraining season. Fertility and Sterility, 44, 755-759.

Sanborn, C.F., Martin, B.J. \& Wagner, W.W. (1982) Is athletic amenorrhea specific to runners? American Journal of Gynecology, 143, 859-863.

Schmid, P., Pusch, H.H., Wolf, W., Pilger, E., Pessenhofer, H., Schwaberger, G., Pristautz, H. \& Purstner, P. (1982) Serum FSH, LH, and testosterone in humans after physical exercise. International Journal of Sports Medicine, 3, 84-89.

Sloan, A.W., Burk, J.J. \& Blythe, C.S. (1962) Estimation of body fat in young women. Journal of Applied Physiology, 17, 967-970.

Urban, R.J., Evans, W.S., Rogol, A.D., Kaiser, D.L., Johnson, M.L. \& J.D. Veldhuis. (1988) Contemporary aspects of discrete peak-detection algorithms. I. The paradigm of the luteinizing hormone pulse signal in men. Endocrine Reviews, 9, 3-37.

Veldhuis, J.D., Evans, W.S., Demers, L.M., Thorner, M.O., Wakat, D. \& Rogol, A.D. (1985) Altered neuroendocrine regulation of gonadotropin secretion in women distance runners. Journal of Clinical Endocrinology and Metabolism, 61, 557-563.

Veldhuis, J.D. \& Johnson, M.L. (1986) Cluster analysis: a simple, versatile and robust algorithm for endocrine pulse detection. American Journal of Physiology, 250, E486-E493.

Vermeulen, H. \& Kaufman, J.M. (1992) Editorial: role of the hypothalmo-pituitary axis in the hypoandrogenism of healthy aging. Journal of Clinical Endocrinology and Metabolism, 75, 704-706.

Yen, S.S.C., Tsai, C.C., Naftolin, F., Vandenberg, G. \& Ajabor, L. (1972) Pulsatile patterns of gonadotropin release in subjects with and without ovarian function. Journal of Chemical Endocrinology and Metabolism, 34, 671-675. 